Article

\title{
Isolation and Characterization of Nanocellulose with a Novel Shape from Walnut (Juglans Regia L.) Shell Agricultural Waste
}

\author{
Dingyuan Zheng ${ }^{1,2}\left(\mathbb{D}\right.$, Yangyang Zhang ${ }^{1,2}$, Yunfeng Guo ${ }^{1,2}$ and Jinquan Yue ${ }^{1,2, *(1)}$ \\ 1 College of Material Science and Engineering, Northeast Forestry University, Harbin 150040, China \\ 2 Key Laboratory of Bio-based Material Science and Technology of Ministry of Education, Northeast Forestry \\ University, 26 Hexing Road, Harbin 150040, China \\ * Correspondence: yuejinq@163.com; Tel.: +86-135-0368-5163
}

Received: 3 June 2019; Accepted: 24 June 2019; Published: 3 July 2019

check for updates

\begin{abstract}
Herein, walnut shell (WS) was utilized as the raw material for the production of purified cellulose. The production technique involves multiple treatments, including alkaline treatment and bleaching. Furthermore, two nanocellulose materials were derived from WS by 2,2,6,6-tetramethylpiperidine-1-oxyl radical (TEMPO) oxidation and sulfuric acid hydrolysis, demonstrating the broad applicability and value of walnuts. The micromorphologies, crystalline structures, chemical functional groups, and thermal stabilities of the nanocellulose obtained via TEMPO oxidation and sulfuric acid hydrolysis (TNC and SNC, respectively) were comprehensively characterized. The TNC exhibited an irregular block structure, whereas the SNC was rectangular in shape, with a length of 55-82 $\mathrm{nm}$ and a width of $49-81 \mathrm{~nm}$. These observations are expected to provide insight into the potential of utilizing WSs as the raw material for preparing nanocellulose, which could address the problems of the low-valued utilization of walnuts and pollution because of unused WSs.
\end{abstract}

Keywords: Walnut shell; nanocellulose; TEMPO oxidation; sulfuric acid hydrolysis; ultrasonication

\section{Introduction}

With the depletion of fossil fuels and the increase in ecological and environmental problems caused by the usage of fossil fuels, the development and utilization of green biomass-based materials derived from renewable natural resources have been extensively studied around the world [1]. Cellulose, which can be observed in all the plant structures, is a common example of a renewable natural resource and offers the advantages of abundant availability, renewability, and biodegradability [2,3]. With the development of nanotechnology, nanocellulose, prepared from cellulose, has attracted significant attention from academic and industrial researchers because of its low cost, biocompatibility, biodegradability, nontoxicity, renewability, sustainability, strong surface reactivity, and desirable physical properties (it is lightweight and impermeable to gas and it also exhibits high stiffness, good optical transparency, and low thermal expansion) [4,5]. Compared with cellulose, nanocellulose exhibits large surface area, high crystallinity, high mechanical strength, high hydrophilicity and supramolecular structure [6]. These characteristics make nanocellulose promising for various applications such as polymer nanocomposites $[7,8]$, packaging $[9,10]$, electronics $[11,12]$, and stimulus-responsive materials [13,14].

Nanocellulose can be extracted from several cellulose resources such as wood [15,16], cotton [17,18], ramie [19], bagasse [20,21], bamboo [22], sisal [23], corn straw [24], rice straw [18], and coconut shell [25]. It has been reported that the fundamental properties of the obtained nanocellulose, such as morphology, 
crystallinity, dimensions, and surface chemistry, vary highly depending on the raw material and the isolation process used to obtain it $[26,27]$. Hence, different categories of nanocellulose, such as cellulose nanofibrils, cellulose nanocrystals, and bacterial cellulose, which differ in terms of their dimensions and morphologies, exist $[2,28]$. These key properties are of critical importance for ensuring the end use of the isolated nanocellulose.

Walnut (Juglans regia L.), also known as a peach, is harvested from the seed of the walnut tree. Walnut is one of the world's four major "dried fruits" along with almonds, cashews, and hazelnuts. The global walnut production in 2017 exceeded 3.8 million tons. The walnut shell (WS) is the hard outer shell (endocarp) of walnut, which comprises cellulose, hemicellulose, lignin, and other small molecular substances and accounts for $67 \%$ of the total weight of walnut [29]. China, which is the top walnut producer in the world, produced 1.92 million tons of walnuts in 2017, which resulted in approximately 1.29 million tons of WSs (UN Food and Agriculture Organization, Corporate Statistical Databas, 2018). After the nut is removed from the WS, the shells are considered to be agricultural and forestry waste, which is often burned as fuel, seriously damaging the environment. Only a small portion of the produced WSs is used for preparing wood-plastic composite materials [30], carbon materials [31,32], or handcrafted products. Thus, the utilization of WSs is not much valued. The walnut contains desirable substances such as cellulose, hemicellulose, and lignin. It has been reported that the cellulose content of walnut shell is about $22 \%$ [33]. Hence, in this study, we investigate the preparation of nanocellulose using WS as the raw material for the first time.

Cellulose nanofibrils are mainly obtained from cellulosic fibers by mechanical treatments such as high-pressure homogenization, microfluidization, grinding, and ultrasonication [34]. However, such mechanical fibrillation methods are very energy intensive. Various pretreatment methods (such as enzymatic hydrolysis [35], 2,2,6,6-tetramethylpiperidine-1-oxyl radical (TEMPO)-mediated oxidation [36-38]) have been proposed to reduce the energy required for the mechanical deconstruction process by reducing the negative or positive charge on the fiber surfaces and by enhancing the colloidal stability of the final cellulose nanofibrils.

Unlike cellulose nanofibrils, cellulose nanocrystals have a rod-like morphology [39]. Cellulose nanocrystals are generally prepared by hydrolysis using a strong inorganic acid such as sulfuric acid $[40,41]$, other inorganic strong acid hydrolysis are used for cellulose nanocrystals preparation as well, including hydrochloric acid, phosphoric acid, hydrobromic acid, and nitric acid [42]. Recent technological developments have resulted in a few sustainable and environment friendly methods that rely on recyclable chemicals. Examples include hydrolysis with solid acids (e.g., phosphor tungstic acid [43]) or treatment with ionic liquids [44] or deep eutectic solvents [45]. Among these, sulfuric acid is the most commonly used acid for producing sulfonated cellulose nanocrystals exhibiting good dispersibility in water [42]. During the hydrolysis process, the paracrystalline or disordered parts of cellulose are hydrolyzed and dissolved in the acid solution; however, the crystalline parts are chemically resistant to the acid and remain intact. Consequently, the cellulose fibrils are transversely cleaved, yielding short cellulose nanocrystals with a relatively high crystallinity [34].

In this study, we aim to isolate nanocellulose from a renewable, cheap, and currently underutilized raw material, i.e., WS. Herein, WS is pretreated using several mechanical and chemical processes, including grinding, extraction, alkali treatment, and bleaching. Nanocellulose was produced by TEMPO oxidation accompanied by ultrasonic treatment (yielding TNC) or sulfuric acid hydrolysis followed by ultrasonication (SNC). The resulting TNC and SNC and the intermediate products were characterized by transmission electron microscopy (TEM), X-ray diffraction (XRD), Fourier-transform infrared spectroscopy (FTIR), and thermogravimetric analysis (TGA). The proposed method of extracting nanocellulose from WSs is expected to reduce the pressure on natural resources. This will offer an alternative high-valued utilization for the currently wasted WSs and, furthermore, to serve as a reference for future studies to improve the utilization of the obtained nanocellulose for developing new biobased nanomaterials. 


\section{Materials and Methods}

\subsection{Materials}

The WS collected from the Shanxi Province in China was used as the raw material. Ethanol, sodium hydroxide, sodium chlorite, sodium bromide, sodium hypochlorite, glacial acetic acid, sulfuric acid, and other chemicals were of analytical grade and used without any further purification. All of the chemicals were supplied by Tianjin Kemiou Chemical Reagent Co., Ltd. (Tianjin, China). Distilled water was used the whole process. TEMPO was purchased from Aladdin Reagent Co., Ltd. (Shanghai, China). Dialysis bags (MD44, viskase, Lombard, IL, USA) were provided by Beijing Biotopped Science \& Technology CO., Ltd. (Beijing, China).

\subsection{Preparation of Nanocellulose}

The procedure used to prepare nanocellulose is outlined in Figure 1.

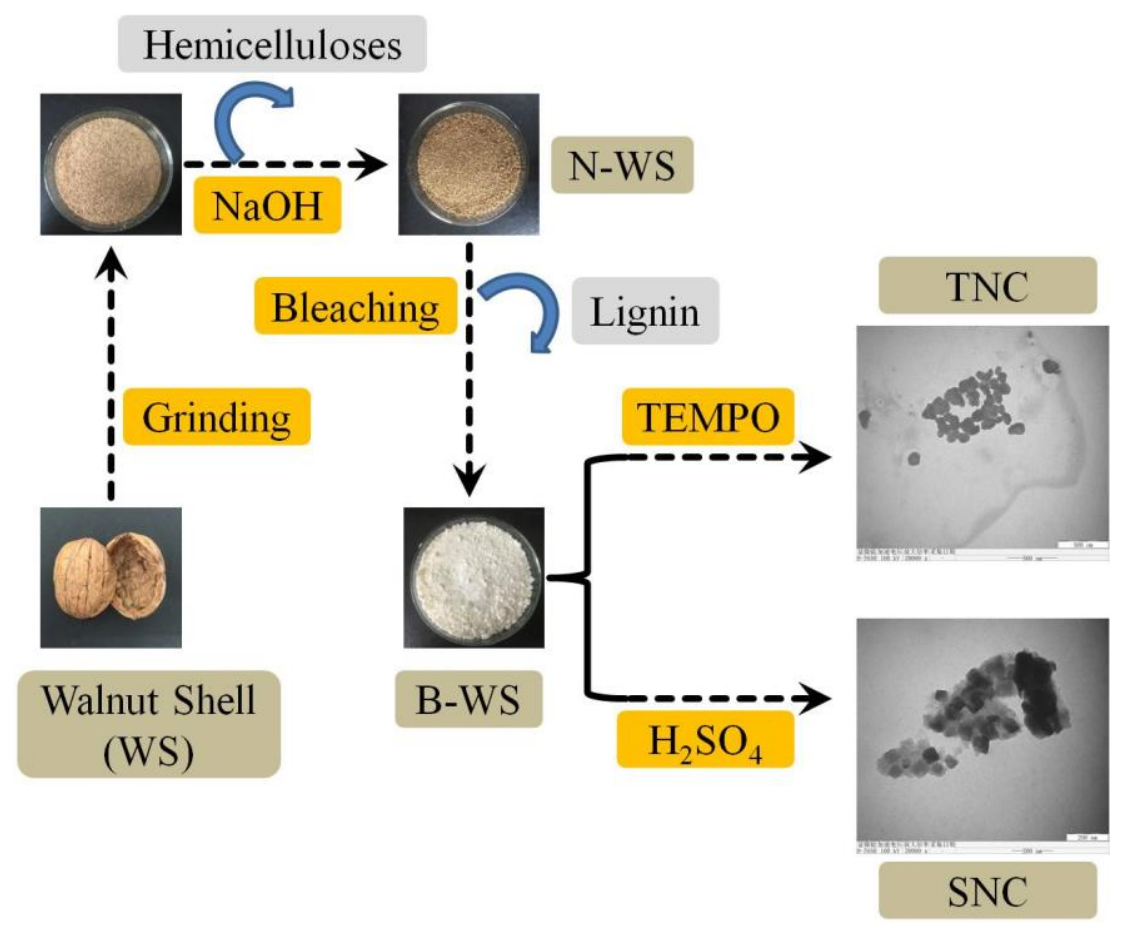

Figure 1. Procedure used to isolate nanocellulose from the walnut shell.

\subsubsection{WS Pretreatment}

In natural WSs, cellulose is embedded in a network structure in which lignin and hemicellulose are linked together, mainly by covalent bonds [46]. Thus, WS was initially pretreated to isolate the nanocellulose. Pretreatment of walnut shell was performed using the method described by de Rodriguez, Thielemans, and Dufresne [47]. The WS was ground and sieved through $60 \mathrm{mesh}(0.25 \mathrm{~mm})$, dried in an oven at $105^{\circ} \mathrm{C}$, and stored in a desiccator. To eliminate hemicellulose, the obtained WS powder was mixed with a $2 \mathrm{wt} . \% \mathrm{NaOH}$ solution in a WS/NaOH solid-to-liquid ratio of $10 \mathrm{~g} / 100 \mathrm{~mL}$ and stirred for $4 \mathrm{~h}$ at $100{ }^{\circ} \mathrm{C}$. This $\mathrm{NaOH}$ treatment was repeated four times until no more discoloration occurred; the product obtained after the $\mathrm{NaOH}$ treatment can be referred to as N-WS. Further, N-WS was bleached in a solution containing equal amounts of acetate buffer and $1.7 \mathrm{wt} . \% \mathrm{NaClO}_{2}$ at a WS/solution solid-to-liquid ratio of $5 \mathrm{~g} / 100 \mathrm{~mL}$ for $6 \mathrm{~h}$ at $80^{\circ} \mathrm{C}$ (the reaction flask was shaken every $20 \mathrm{~min}$ to ensure the reaction occurs evenly). This bleaching process was repeated four times. The bleached products were then thoroughly washed using distilled water. The obtained product can be referred to as B-WS. 


\subsubsection{TNC Preparation}

TNC was prepared using the method described by Kuramae, Saito, and Isogai [48], with few modifications. One gram of B-WS was dispersed in $100 \mathrm{~mL}$ of distilled water; further, $0.1 \mathrm{~g}$ of sodium bromide and $0.016 \mathrm{~g}$ of TEMPO were added, followed by $20 \mathrm{mmol}$ of $\mathrm{NaClO}$. During the TEMPO oxidation, the $\mathrm{pH}$ of the suspension was adjusted to $10 \pm 0.5$ using $0.1 \mathrm{M} \mathrm{NaOH}$ and $0.1 \mathrm{M} \mathrm{HCl}$. The reaction was continued for $5 \mathrm{~h}$ at room temperature under magnetic stirring at $1000 \mathrm{rpm}$ and was terminated by adding $10 \mathrm{~mL}$ of ethanol. The oxidized B-WS was washed and filtered; subsequently, it was stored with distilled water at $4{ }^{\circ} \mathrm{C}$ to avoid strong hydrogen bonding.

To convert the nonoxidized hydroxyl and aldehyde groups in the oxidized B-WS into carboxyl groups, the product obtained in the previous step was further processed. One gram of oxidized B-WS (dry weight) was dispersed in $65 \mathrm{~mL}$ of distilled water, and the $\mathrm{pH}$ value was adjusted to $4-5$. Further, $0.6 \mathrm{~g}$ of $\mathrm{NaClO}_{2}$ was added to the reaction system. The reaction was allowed to proceed for $1 \mathrm{~h}$ at $70{ }^{\circ} \mathrm{C}$ under magnetic stirring at $1000 \mathrm{rpm}$ to yield carboxylated B-WS. The obtained carboxylated B-WS had a carboxylate content of $1.12 \mathrm{mmol} / \mathrm{g}$ as determined by conductivity titration [49]. A certain amount of carboxylated B-WS was weighed, and the mass fraction was adjusted to $0.5 \mathrm{wt} . \%$. Finally, high-intensity ultrasonication was performed in an ultrasonic cell pulverizer (SCIENTZ-1200E, Ningbo Scientz Biotechnology Co., Ltd., Ningbo, China) at $600 \mathrm{w}$ for $30 \mathrm{~min}$ in an ice/water bath to yield TNC.

\subsubsection{SNC Preparation}

SNC was prepared using the method described by Beck-Candanedo [41]. One gram of B-WS was added to $8.75 \mathrm{~mL}$ of the sulfuric acid solution (64 wt.\%) under vigorous stirring, and the hydrolysis reaction was allowed to proceed for $1 \mathrm{~h}$ at $45^{\circ} \mathrm{C}$. The reaction was ended by adding distilled water in a volume that was ten times the reaction volume. The obtained suspension was washed by mixing with distilled water followed by centrifugation at 12,000 rpm for $15 \mathrm{~min}$ to eliminate the excess acid; the washing was repeated until the precipitate generation was terminated. The suspension was subsequently dialyzed against distilled water until the $\mathrm{pH}$ became 6.5-7. The dialyzed suspension was sonicated at $600 \mathrm{w}$ for $2 \mathrm{~min}$ to yield SNC.

\subsection{Characterization of TNC, SNC, and Intermediate Products}

\subsubsection{Analysis of the Chemical Components}

The $\alpha$-cellulose content was determined as follows [50]. Two grams of WS powder was weighed and transferred to a $250-\mathrm{mL}$ Erlenmeyer flask, and $25 \mathrm{~mL}$ of nitric acid/ethanol solution (1:4 by volume) was added. The mixed solution was refluxed for $1 \mathrm{~h}$, and the process was repeated several times until the sample turned white. The powder was repeatedly washed using distilled water and filtered until the $\mathrm{pH}$ became neutral; the obtained residue was dried at $105^{\circ} \mathrm{C}$. The $\alpha$-cellulose content $(X, \%)$ was calculated as follows

$$
X=\frac{G}{G_{1}(1-W)} \times 100
$$

where $G$ denotes the weight of the obtained residue, $G_{1}$ denotes the weight of the WS, and $W$ denotes the moisture content of the WS.

The remaining chemical components of WS (organic extracts, lignin, hemicellulose, ash, and holocellulose) were analyzed according to the Technical Association of Pulp and Paper Industry standards that have been previously described [51].

\subsubsection{Scanning Electron Microscopy}

The WS, N-WS, B-WS, TNC, and SNC microstructures were observed using a scanning electron microscope (SU8010, Hitachi, Japan) at an accelerating voltage of $5.0 \mathrm{kV}$. TNC and SNC were freeze-dried before observation. All the samples were coated with gold. 


\subsubsection{Transmission Electron Microscopy}

TNC and SNC were imaged using a transmission electron microscope (H-7650 Hitachi, Japan) at a $100-\mathrm{kV}$ acceleration voltage. The TNC and SNC suspensions were diluted to a concentration of $0.01 \%$ and deposited onto carbon-coated grids (230 mesh, Beijing Zhongjingkeyi Technology Co., Ltd., Beijing, China). After drying, the samples were negatively stained using a $1 \%$ phosphotungstic acid solution for $10 \mathrm{~min}$. The TEM images were analyzed using Nanomeasurer 1.2 (Department of Chemistry, Fudan Univ., Shanghai, China) to determine the TNC and SNC size distributions.

\subsubsection{Fourier-transform Infrared Spectroscopy}

The FTIR spectra of WS, N-WS, B-WS, TNC, and SNC were recorded on a Fourier-transform infrared instrument (Nicolette 6700, Thermo Fisher Scientific Inc., Waltham, MA, USA) in 400-4000 $\mathrm{cm}^{-1}$ with a resolution of $4 \mathrm{~cm}^{-1}$, and 20 scans for each sample were conducted. The FTIR spectra of all samples were collected using the attenuated total reflection technique (ATR, the ATR crystal material is zinc selenide ( $\mathrm{ZnSe})$ ).

\subsubsection{X-ray Diffraction Technique}

XRD analysis was performed on WS, N-WS, B-WS, TNC, and SNC using a diffractometer (D/max 2200, Rigaku, Japan) equipped with Ni-filtered $\mathrm{Cu} K \alpha$ radiation $(\lambda=1.5406 \AA)$ at $40 \mathrm{kV}$ and $30 \mathrm{~mA}$. The diffraction intensities were recorded in $2 \theta=5^{\circ}-60^{\circ}$ with a scan rate of $5^{\circ} / \mathrm{min}$. follows

The crystallinity index (CrI, \%) was calculated according to the method reported by Segal [52] as

$$
C r I=\frac{I_{200}-I_{a m}}{I_{200}} \times 100
$$

where $I_{200}$ is the maximum intensity of the diffraction at 200 peak $\left(2 \theta=22.6^{\circ}\right)$ and $I_{a m}$ is the intensity of the diffraction at $2 \theta=18^{\circ}$.

\subsubsection{Thermogravimetric Analysis}

The thermal stability of each sample was evaluated using a thermogravimetric analyzer (TG209F1, Netzsch Scientific Instruments Trading (Shanghai) Co., Ltd., Shanghai, China) from room temperature to $600{ }^{\circ} \mathrm{C}$ at a rate of $10^{\circ} \mathrm{C} / \mathrm{min}$ in a nitrogen atmosphere.

\section{Results and Discussion}

\subsection{Chemical Components}

Table 1 presents the WS, N-WS, and B-WS chemical compositions. The chemical compositions of the three samples were observed to be significantly different because of the applied chemical treatments.

Table 1. Chemical components of walnut shell WS, walnut shell treated by $\mathrm{NaOH}(\mathrm{N}-\mathrm{WS})$, and walnut shell after bleaching (B-WS).

\begin{tabular}{cccccc}
\hline Sample & $\begin{array}{c}\alpha \text {-Cellulose } \\
\mathbf{( \% )}\end{array}$ & Lignin (\%) & $\begin{array}{c}\text { Hemicelluloses } \\
\mathbf{( \% )}\end{array}$ & Ash (\%) & $\begin{array}{c}\text { Benzene/Ethanol } \\
\text { Extractives (\%) }\end{array}$ \\
\hline WS & 27.4 & 36.31 & 31.3 & 3.6 & 1.57 \\
N-WS & 56.6 & 30.98 & 7.6 & 1.97 & 1.16 \\
B-WS & 87.9 & 0.17 & 1.8 & 1.64 & 0.41 \\
\hline
\end{tabular}

It is found that WS has the lowest percentage of cellulose and highest percentage of noncellulosic components such as lignin and hemicelluloses. The chemical treatments aim to remove the noncellulosic components. When WS was subjected to $\mathrm{NaOH}$ treatment, the lignin and hemicelluloses contents of N-WS decreased to $30.98 \%$ and $7.6 \%$, respectively, whereas the cellulose concentration of N-WS 
increased to $56.6 \%$. After bleaching treatment, the cellulose content of B-WS increased to $87.9 \%$ due to the removal of remaining lignin and hemicelluloses, resulting in highly purified cellulose.

\subsection{SEM Analysis}

The WS, N-WS, B-WS, TNC, and SNC microstructures were observed using a scanning electron microscope. The SEM image of WS (Figure 2a) denotes that the WS had a rough surface. However, the surface of N-WS (as seen in Figure 2b) had an irregular porous structure due to the degradation of hemicellulose and the partial degradation of lignin by the repeated alkali treatment. Further, B-WS (shown in Figure 2c) exhibited a loose structure, which indicated the successful removal of residual lignin by the acetate buffer $/ \mathrm{NaClO}_{2}$ solution. These results are consistent with the changes in chemical composition denoted in Table 1.

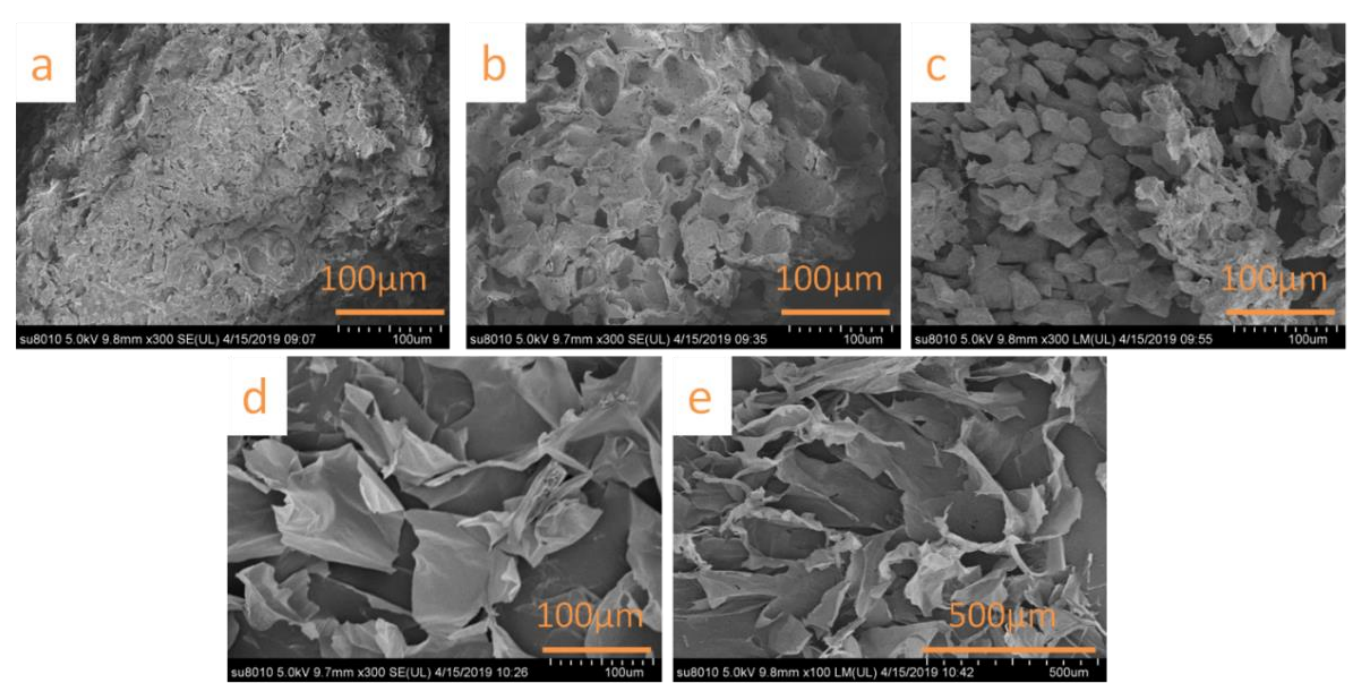

Figure 2. SEM micrographs of (a) WS, (b) N-WS, (c) B-WS, (d) nanocellulose obtained via TEMPO oxidation (TNC), and (e) nanocellulose obtained via sulfuric acid hydrolysis (SNC).

After the TNC was freeze-dried, the obtained aerogel was observed to be a porous network with a lamellar structure (Figure 2d). This structure is because the strong hydrogen bonding during freeze-drying caused the nanoparticles to self-assemble into the lamellar structures [53,54]. The aerogel formed by freeze-drying the SNC exhibited a similar porous structure (Figure 2e).

\subsection{TEM Analysis}

TEM was used to observe the morphology of the nanocellulose produced using different methods. The prepared TNC (Figure 3a) exhibited an irregular block structure, whereas the prepared SNC (Figure $3 \mathrm{~b}$ ) was rectangular with a length of $55-82 \mathrm{~nm}$ and a width of $49-81 \mathrm{~nm}$. The TNC morphology observed in this study was significantly different from that of the nanocellulose produced using the same procedure in a previous study [36,54]; this may be attributed to the irregular morphological structure [30] of the WS powder used in this study, as depicted in Figure 2a. Furthermore, the SNC morphology obtained through sulfuric acid hydrolysis as observed by TEM differed from the typical rod- or needle-like morphologies of the typical cellulose nanocrystals [2]. As has been reported, the size and shape of nanocelluloses influence the properties (for example, optical characteristics, stability, and rheology) in aqueous media [55], which largely determines the application of nanocellulose. Nanocellulose with spherical or square structure makes them excellent candidates as stabilizer for Pickering emulsion [53] or drug delivery carrier for encapsulation [56]. 


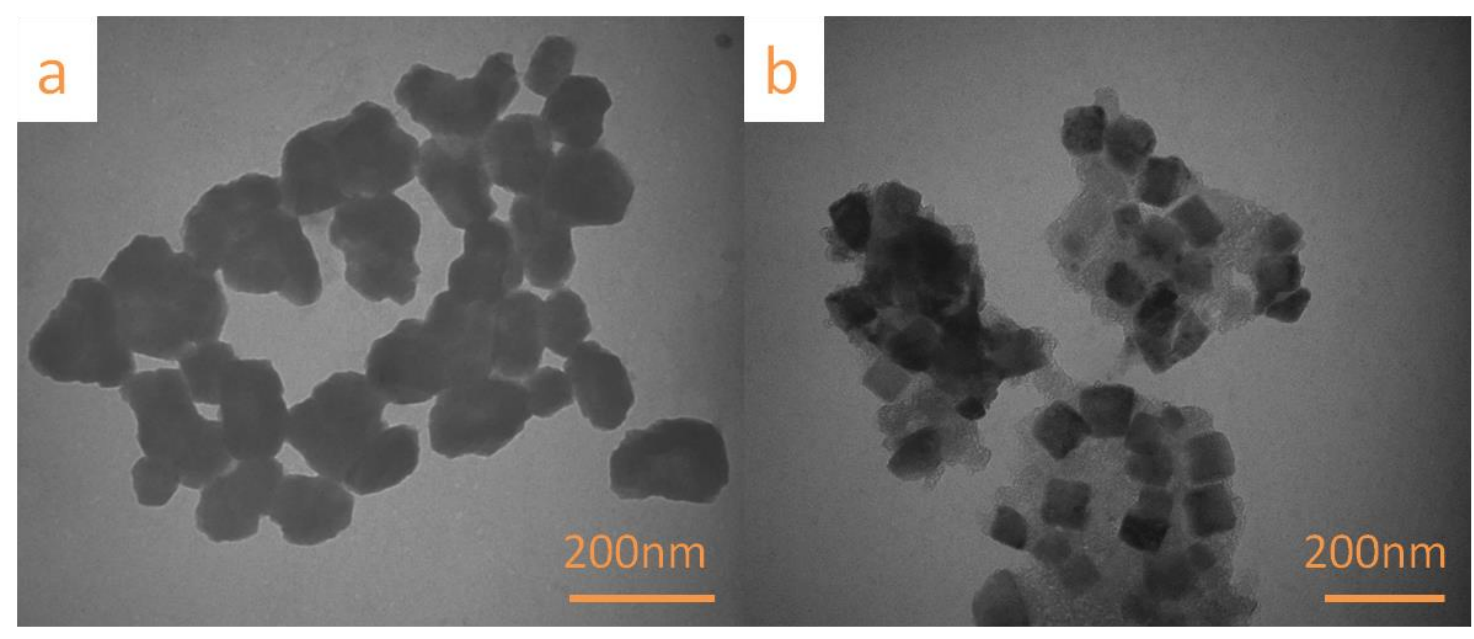

Figure 3. TEM images of (a) TNC and (b) SNC.

\subsection{Chemical Structures}

The changes in the chemical structures of the raw WS after various treatments were investigated using FTIR (Figure 4). Two main absorption regions appeared in all the curves among which one was in the high-wave-number region from 2800 to $3500 \mathrm{~cm}^{-1}$ and the other was in the low-wave-number region from 600 to $1750 \mathrm{~cm}^{-1}$ [57]. The peak at $2897 \mathrm{~cm}^{-1}$ was attributed to the stretching vibration of the $\mathrm{C}-\mathrm{H}$ groups of cellulose, whereas the wide region around $3350 \mathrm{~cm}^{-1}$ was attributed to the $\mathrm{O}-\mathrm{H}$ stretching vibration of the hydrogen-bonded hydroxyl groups in the cellulose molecules $[51,58]$. Further, the peak at $1738 \mathrm{~cm}^{-1}$ corresponds to the acetyl groups and ironic esters of the hemicellulose and the ester linkages of the carboxylic groups of the ferulic and p-coumaric acid in lignin and hemicellulose [59]. The absence of a peak at $1738 \mathrm{~cm}^{-1}$ in the FTIR spectrum of N-WS indicates that the hemicellulose in WS was effectively degraded by the $\mathrm{NaOH}$ treatment. The peaks at $1248 \mathrm{~cm}^{-1}$ and $1502 \mathrm{~cm}^{-1}$ in the FTIR spectrum of WS, corresponding to the aromatic skeletal vibrations of lignin [60], disappeared in the curve of B-WS, confirming that majority of the lignin was removed by the bleaching treatment. Furthermore, the absence of peaks at $1738 \mathrm{~cm}^{-1}, 1502 \mathrm{~cm}^{-1}$, and $1248 \mathrm{~cm}^{-1}$ in the B-WS spectrum is consistent with the changes in chemical components during the alkaline and bleaching processes. The absorption peaks at $1162 \mathrm{~cm}^{-1}$ and $1034 \mathrm{~cm}^{-1}$ in all the curves correspond to the stretching vibration of the $\mathrm{C}-\mathrm{O}-\mathrm{C}$ bonds in the 1,4-glycosidic links linkages of the $\mathrm{D}$-glucose units in cellulose, which were interpreted as typical for a cellulose structure [61]. The peaks at approximately $1645 \mathrm{~cm}^{-1}$ in the spectra of all the samples were attributed to the $\mathrm{H}-\mathrm{O}-\mathrm{H}$ stretching vibration of the adsorbed water due to the hydroxyl groups in cellulose [20], whereas those at $892 \mathrm{~cm}^{-1}$ represented the $\mathrm{C}_{1}-\mathrm{H}$ deformation of cellulose [62]. There were no significant differences between the SNC and B-WS spectra, demonstrating that the characteristics of the cellulose molecular structure were maintained during sulfuric acid hydrolysis. The increase in the relative amount of cellulose in the sample due to the decrease in the amounts of other components upon hydrolysis may account for the slight increase in the intensity of the peak at $1034 \mathrm{~cm}^{-1}$ from B-WS to SNC. The peak at $1738 \mathrm{~cm}^{-1}$, which is characteristic of the $\mathrm{C}=\mathrm{O}$ stretching of carboxyl groups, reappeared in the FTIR spectrum of TNC when compared with that of B-WS due to the introduction of - $\mathrm{COOH}$ on the cellulose surface; this indicates that cellulose was successfully modified by the TEMPO oxidation [63]. 


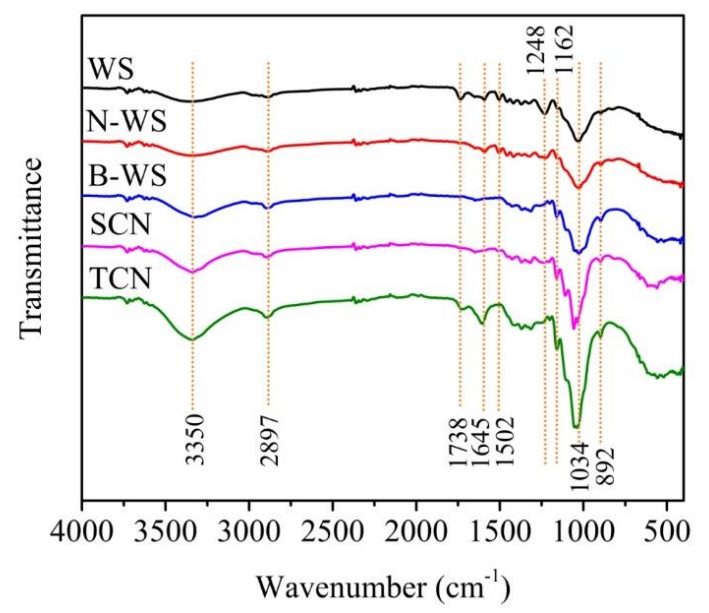

Figure 4. FTIR spectra of WS, N-WS, B-WS, TNC, and SNC.

\subsection{Crystal Structures}

The XRD patterns of WS, N-WS, B-WS, TNC, and SNC (Figure 5) were studied to further evaluate the influence of the processing treatment. All the samples exhibited diffraction peaks at approximately $16^{\circ}(110)$ and $22.6^{\circ}$ (200), whereas WS, N-WS, and B-WS also exhibited a diffraction peak at approximately $34^{\circ}(004)$. These peaks indicate that the typical cellulose crystal structure was preserved in all the samples, indicating that the chemical and ultrasonic treatments did not change the integrity of the original cellulose crystal $[64,65]$. However, the crystallinity index changed with each step. The apparent crystallinity of WS was $29.5 \%$. After $\mathrm{NaOH}$ treatment, the CrI of N-WS increased to $40.9 \%$ due to the dissolution and removal of lignin and majority of the hemicellulose (i.e., the amorphous hemicellulose) [57]. The CrI further increased to $42.9 \%$ as a result of the lignin removal by the acetate buffer $/ \mathrm{NaClO}_{2}$ solution. These results are consistent with the observed changes in the chemical composition and the FTIR analyses. The CrI of SNC (40.1\%) decreased slightly after the sulfuric acid hydrolysis and ultrasonication, which may have been caused because the amorphous and crystalline regions were damaged by the strong acid hydrolysis [66]. There were no significant differences in the position of X-ray diffraction peaks between the TNC and B-WS XRD curves, indicating that the original crystal structure of the cellulose was unchanged after the oxidation (Figure 5). These results indicate that the carboxylate groups formed by the TEMPO-mediated oxidation are selectively introduced on the surfaces of the cellulose microfibril rather than the internal cellulose crystallites [38].

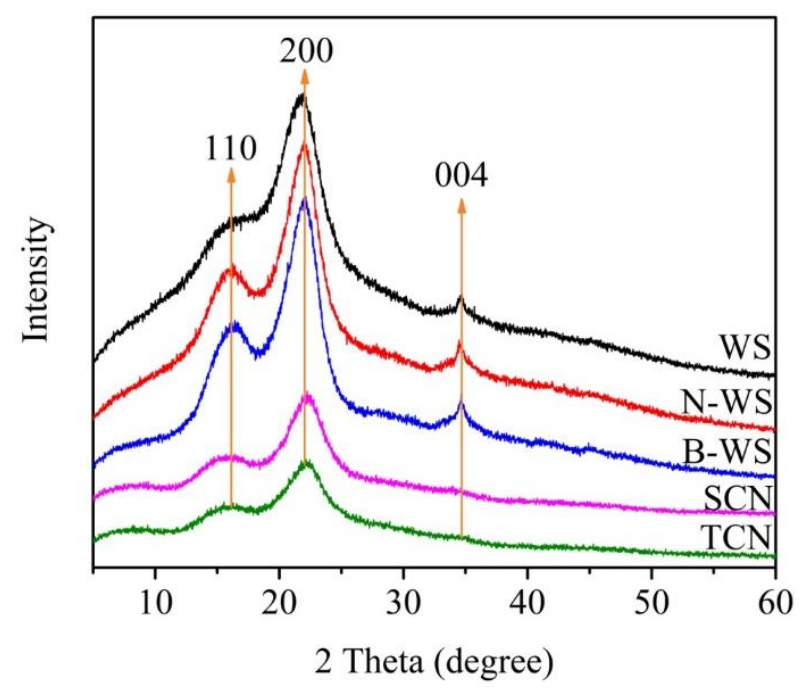

Figure 5. XRD patterns of WS, N-WS, B-WS, TNC, and SNC. 


\subsection{Thermal Stability}

Figures 6 and 7 depicted the TGA and DTG curves, respectively, for WS, N-WS, B-WS, TNC, and SNC. All the TGA curves began with slight mass losses from room temperature to $105^{\circ} \mathrm{C}$, corresponding to the evaporation of slightly bound water from all the samples. As the temperature increased further, the WS degradation occurred in two phases. The first decomposition occurred between $214{ }^{\circ} \mathrm{C}$ and 300 ${ }^{\circ} \mathrm{C}$, corresponding to the hemicellulose degradation and the beginning of lignin degradation $[23,67]$. After this change, the largest loss of mass in the material occurred between $300^{\circ} \mathrm{C}$ and $380^{\circ} \mathrm{C}$, peaking at $342{ }^{\circ} \mathrm{C}$, which corresponded to that of cellulose [68].

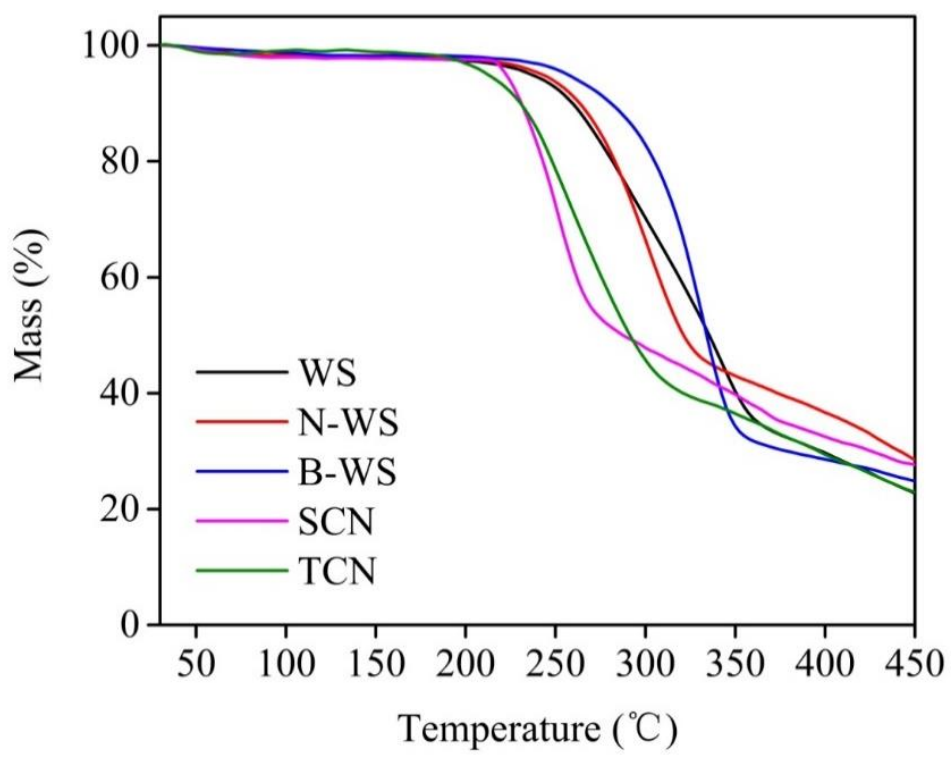

Figure 6. TGA curves of WS, N-WS, B-WS, TNC, and SNC.

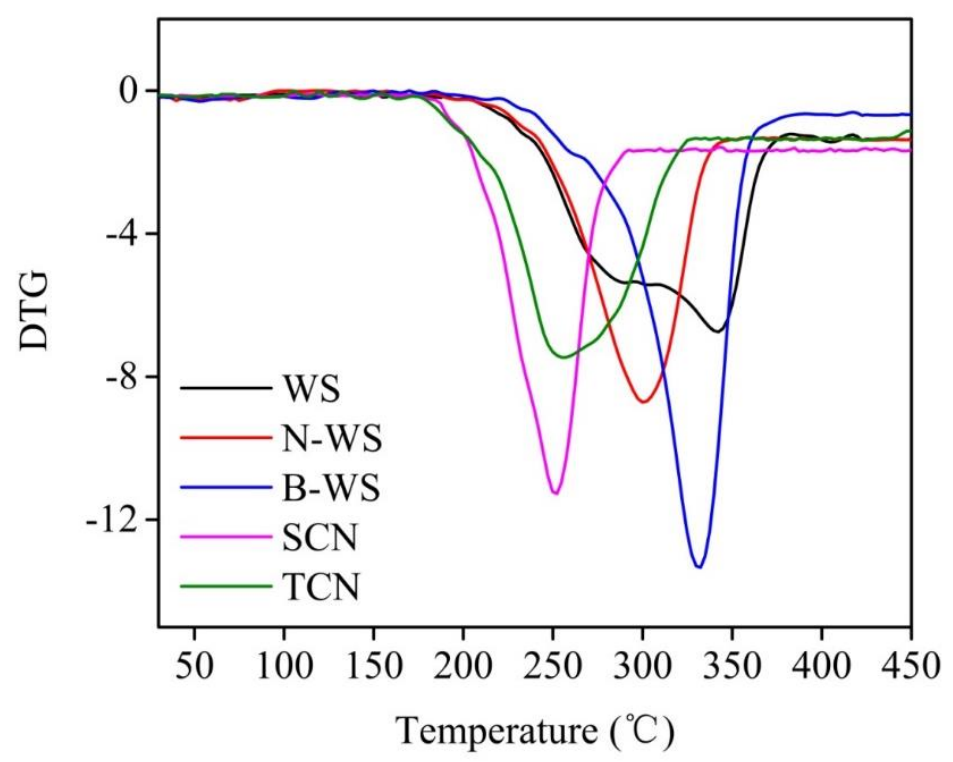

Figure 7. DTG curves of WS, N-WS, B-WS, TNC, and SNC.

In contrast, the decomposition of four other samples occurred in only one stage. N-WS began to degrade at $205^{\circ} \mathrm{C}$ due to lignin degradation; however, the maximum mass loss occurred at $301^{\circ} \mathrm{C}$, which can be attributed to cellulose degradation. The absence of peaks related to the degradation of hemicellulose and the relatively small change associated with lignin degradation in this sample as 
compared with that associated with WS indicates that the alkaline treatment eliminated most of the hemicellulose and some of the lignin from the WS.

B-WS degraded from 222 to $380{ }^{\circ} \mathrm{C}$, with the most significant mass loss occurring at $332{ }^{\circ} \mathrm{C}$; this was mainly attributed to cellulose degradation, which was within the decomposition temperature range reported in previous studies $[68,69]\left(315-400^{\circ} \mathrm{C}\right)$. The wide range, which was associated with lignin degradation, was not observed in this sample, indicating that lignin was eliminated after the bleaching reaction in the acetate buffer $/ \mathrm{NaClO}_{2}$ solution.

The thermal degradation of TNC (i.e., following TEMPO/NaClO/NaBr oxidation) began at $178{ }^{\circ} \mathrm{C}$, which was approximately $50{ }^{\circ} \mathrm{C}$ lower than that in B-WS. It has been reported that the introduction of $-\mathrm{COOH}$ by the TEMPO-mediated oxidation of the $\mathrm{C} 6$ primary hydroxyl groups on the cellulose surface results in a significant decrease in thermal degradation [70].

SNC exhibited the worst thermal stability among the five tested samples, which can be attributed to the introduction of sulfate groups. It had been reported that the degradation of sulfate groups requires relatively low activation energy [71,72]. The thermal stability of TNC was likely to be lower than that of SNC because it exhibited fewer crystalline regions. This result is consistent with those in previous studies $[73,74]$, which have shown that the crystalline regions of nanocellulose generally provide thermal stability. This finding is in agreement with the finding of XRD analyses, which showed that TNC had a high crystallinity index.

\section{Conclusions}

In this study, nanocellulose was produced using WS as the raw material; novel shapes were obtained by applying different production processes. The chemical composition analysis revealed that the hemicellulose and lignin in WS were effectively removed by alkali treatment and bleaching, increasing the cellulose content to $89 \%$. The TEM images denoted that the produced TNC exhibited an irregular block structure, whereas SNC was rectangular with a length of 55-82 nm and a width of 49-81 nm. The results of the FTIR and XRD analyses of WS, N-WS, and B-WS were consistent with the observed chemical changes and confirmed that the typical cellulose structure remained unchanged through the TEMPO oxidation and sulfuric acid hydrolysis treatments. Our observations demonstrate that WSs, which are an abundant and sustainable agricultural waste, may be repurposed for the production of nanocellulose.

Author Contributions: Conceptualization, D.Z.; Formal analysis, D.Z.; Investigation, D.Z.; Methodology, D.Z.; Project administration, J.Y.; Resources, J.Y.; Supervision, J.Y.; Validation, Y.Z. and Y.G.; Writing一original draft, D.Z.; Writing-review \& editing, D.Z. and J.Y.

Funding: This research received no external funding.

Acknowledgments: The authors express their appreciation to Key Laboratory of Biobased Material Science and Technology of Ministry of Education and College of Material Science and Engineering of Northeast Forestry University for full support of this research.

Conflicts of Interest: The authors declare no conflict of interest.

\section{Abbreviations}

WS walnut shell

N-WS walnut shell treated by $\mathrm{NaOH}$

B-WS walnut shell after bleaching

TNC nanocellulose obtained via TEMPO oxidation

SNC nanocellulose obtained via sulfuric acid hydrolysis

\section{References}

1. Harini, K.; Ramya, K.; Sukumar, M. Extraction of nano cellulose fibers from the banana peel and bract for production of acetyl and lauroyl cellulose. Carbohydr. Polym. 2018, 201, 329-339. [CrossRef] [PubMed] 
2. Kontturi, E.; Laaksonen, P.; Linder, M.B.; Groschel, A.H.; Rojas, O.J.; Ikkala, O. Advanced Materials through Assembly of Nanocelluloses. Adv. Mater. 2018, 30, 39. [CrossRef] [PubMed]

3. Moreau, C.; Villares, A.; Capron, I.; Cathala, B. Tuning supramolecular interactions of cellulose nanocrystals to design innovative functional materials. Ind. Crop. Prod. 2016, 93, 96-107. [CrossRef]

4. Zhuo, X.; Liu, C.; Pan, R.T.; Dong, X.Y.; Li, Y.F. Nanocellulose Mechanically Isolated from Amorpha fruticosa Linn. ACS Sustain. Chem. Eng. 2017, 5, 4414-4420. [CrossRef]

5. Munch, A.S.; Wolk, M.; Malanin, M.; Eichhorn, K.J.; Simon, F.; Uhlmann, P. Smart functional polymer coatings for paper with anti-fouling properties. J. Mat. Chem. B 2018, 6, 830-843. [CrossRef]

6. Klemm, D.; Kramer, F.; Moritz, S.; Lindstrom, T.; Ankerfors, M.; Gray, D.; Dorris, A. Nanocelluloses: A New Family of Nature-Based Materials. Angew. Chem. Int. Ed. 2011, 50, 5438-5466. [CrossRef] [PubMed]

7. Kargarzadeh, H.; Mariano, M.; Huang, J.; Lin, N.; Ahmad, I.; Dufresne, A.; Thomas, S. Recent developments on nanocellulose reinforced polymer nanocomposites: A review. Polymer 2017, 132, 368-393. [CrossRef]

8. Fujisawa, S.; Togawa, E.; Kuroda, K. Facile Route to Transparent, Strong, and Thermally Stable Nanocellulose/Polymer Nanocomposites from an Aqueous Pickering Emulsion. Biomacromolecules 2017, 18, 266-271. [CrossRef] [PubMed]

9. Khan, A.; Huq, T.; Khan, R.A.; Riedl, B.; Lacroix, M. Nanocellulose-Based Composites and Bioactive Agents for Food Packaging. Crit. Rev. Food Sci. Nutr. 2014, 54, 163-174. [CrossRef] [PubMed]

10. El-Wakil, N.A.; Hassan, E.A.; Abou-Zeid, R.E.; Dufresne, A. Development of wheat gluten/nanocellulose/titanium dioxide nanocomposites for active food packaging. Carbohydr. Polym. 2015, 124, 337-346. [CrossRef] [PubMed]

11. Wang, Z.; Tammela, P.; Stromme, M.; Nyholm, L. Nanocellulose coupled flexible polypyrrole@graphene oxide composite paper electrodes with high volumetric capacitance. Nanoscale 2015, 7, 3418-3423. [CrossRef] [PubMed]

12. Chen, W.; Yu, H.; Lee, S.-Y.; Wei, T.; Li, J.; Fan, Z. Nanocellulose: A promising nanomaterial for advanced electrochemical energy storage. Chem. Soc. Rev. 2018, 47, 2837-2872. [CrossRef] [PubMed]

13. Liu, Y.; Li, Y.; Yang, G.; Zheng, X.T.; Zhou, S.B. Multi-Stimulus-Responsive Shape-Memory Polymer Nanocomposite Network Cross-Linked by Cellulose Nanocrystals. ACS Appl. Mater. Interfaces 2015, 7, 4118-4126. [CrossRef] [PubMed]

14. Wang, Y.; Heim, L.-O.; Xu, Y.; Buntkowsky, G.; Zhang, K. Transparent, Stimuli-Responsive Films from Cellulose-Based Organogel Nanoparticles. Adv. Funct. Mater. 2015, 25, 1434-1441. [CrossRef]

15. Rajinipriya, M.; Nagalakshmaiah, M.; Robert, M.; Elkoun, S. Importance of Agricultural and Industrial Waste in the Field of Nanocellulose and Recent Industrial Developments of Wood Based Nanocellulose: A Review. ACS Sustain. Chem. Eng. 2018, 6, 2807-2828. [CrossRef]

16. Inamochi, T.; Funahashi, R.; Nakamura, Y.; Saito, T.; Isogai, A. Effect of coexisting salt on TEMPO-mediated oxidation of wood cellulose for preparation of nanocellulose. Cellulose 2017, 24, 4097-4101. [CrossRef]

17. Saraiva Morais, J.P.; Rosa, M.D.F.; Moreira de Souza Filho, M.D.S.; Nascimento, L.D.; do Nascimento, D.M.; Cassales, A.R. Extraction and characterization of nanocellulose structures from raw cotton linter. Carbohydr. Polym. 2013, 91, 229-235. [CrossRef] [PubMed]

18. Hsieh, Y.-L. Cellulose nanocrystals and self-assembled nanostructures from cotton, rice straw and grape skin: A source perspective. J. Mater. Sci. 2013, 48, 7837-7846. [CrossRef]

19. Syafri, E.; Kasim, A.; Abral, H.; Sulungbudi, G.T.; Sanjay, M.R.; Sari, N.H. Synthesis and characterization of cellulose nanofibers (CNF) ramie reinforced cassava starch hybrid composites. Int. J. Biol. Macromol. 2018, 120, 578-586. [CrossRef]

20. Mandal, A.; Chakrabarty, D. Isolation of nanocellulose from waste sugarcane bagasse (SCB) and its characterization. Carbohydr. Polym. 2011, 86, 1291-1299. [CrossRef]

21. Li, J.; Wei, X.; Wang, Q.; Chen, J.; Chang, G.; Kong, L.; Su, J.; Liu, Y. Homogeneous isolation of nanocellulose from sugarcane bagasse by high pressure homogenization. Carbohydr. Polym. 2012, 90, 1609-1613. [CrossRef] [PubMed]

22. Brito, B.S.L.; Pereira, F.V.; Putaux, J.-L.; Jean, B. Preparation, morphology and structure of cellulose nanocrystals from bamboo fibers. Cellulose 2012, 19, 1527-1536. [CrossRef]

23. Moran, J.I.; Alvarez, V.A.; Cyras, V.P.; Vazquez, A. Extraction of cellulose and preparation of nanocellulose from sisal fibers. Cellulose 2008, 15, 149-159. [CrossRef] 
24. Hernandez, C.C.; Ferreira, F.F.; Rosa, D.S. X-ray powder diffraction and other analyses of cellulose nanocrystals obtained from corn straw by chemical treatments. Carbohydr. Polym. 2018, 193, 39-44. [CrossRef] [PubMed]

25. Wan, C.; Lu, Y.; Jiao, Y.; Jin, C.; Sun, Q.; Li, J. Ultralight and hydrophobic nanofibrillated cellulose aerogels from coconut shell with ultrastrong adsorption properties. J. Appl. Polym. Sci. 2015, 132. [CrossRef]

26. Sacui, I.A.; Nieuwendaal, R.C.; Burnett, D.J.; Stranick, S.J.; Jorfi, M.; Weder, C.; Foster, E.J.; Olsson, R.T.; Gilman, J.W. Comparison of the Properties of Cellulose Nanocrystals and Cellulose Nanofibrils Isolated from Bacteria, Tunicate, and Wood Processed Using Acid, Enzymatic, Mechanical, and Oxidative Methods. ACS Appl. Mater. Interfaces 2014, 6, 6127-6138. [CrossRef] [PubMed]

27. Deepa, B.; Abraham, E.; Cordeiro, N.; Mozetic, M.; Mathew, A.P.; Oksman, K.; Faria, M.; Thomas, S.; Pothan, L.A. Utilization of various lignocellulosic biomass for the production of nanocellulose: A comparative study. Cellulose 2015, 22, 1075-1090. [CrossRef]

28. Garcia, A.; Gandini, A.; Labidi, J.; Belgacem, N.; Bras, J. Industrial and crop wastes: A new source for nanocellulose biorefinery. Ind. Crop. Prod. 2016, 93, 26-38. [CrossRef]

29. Pirayesh, H.; Khazaeian, A.; Tabarsa, T. The potential for using walnut (Juglans regia L.) shell as a raw material for wood-based particleboard manufacturing. Compos. Part B Eng. 2012, 43, 3276-3280. [CrossRef]

30. Ayrilmis, N.; Kaymakci, A.; Ozdemir, F. Physical, mechanical, and thermal properties of polypropylene composites filled with walnut shell flour. J. Ind. Eng. Chem. 2013, 19, 908-914. [CrossRef]

31. Yang, J.; Qiu, K. Preparation of activated carbons from walnut shells via vacuum chemical activation and their application for methylene blue removal. Chem. Eng. J. 2010, 165, 209-217. [CrossRef]

32. Martinez, M.L.; Torres, M.M.; Guzman, C.A.; Maestri, D.M. Preparation and characteristics of activated carbon from olive stones and walnut shells. Ind. Crop. Prod. 2006, 23, 23-28. [CrossRef]

33. Demirbas, A. Relationships between lignin contents and fixed carbon contents of biomass samples. Energy Conv. Manag. 2003, 44, 1481-1486. [CrossRef]

34. Kim, J.-H.; Lee, D.; Lee, Y.-H.; Chen, W.; Lee, S.-Y. Nanocellulose for Energy Storage Systems: Beyond the Limits of Synthetic Materials. Adv. Mater. 2019, 31, e1804826. [CrossRef]

35. Chen, X.-Q.; Deng, X.-Y.; Shen, W.-H.; Jia, M.-Y. Preparation and characterization of the spherical nanosized cellulose by the enzymatic hydrolysis of pulp fibers. Carbohydr. Polym. 2018, 181, 879-884. [CrossRef]

36. Saito, T.; Kimura, S.; Nishiyama, Y.; Isogai, A. Cellulose nanofibers prepared by TEMPO-mediated oxidation of native cellulose. Biomacromolecules 2007, 8, 2485-2491. [CrossRef]

37. Okita, Y.; Saito, T.; Isogai, A. Entire Surface Oxidation of Various Cellulose Microfibrils by TEMPO-Mediated Oxidation. Biomacromolecules 2010, 11, 1696-1700. [CrossRef]

38. Isogai, A.; Saito, T.; Fukuzumi, H. TEMPO-oxidized cellulose nanofibers. Nanoscale 2011, 3, 71-85. [CrossRef]

39. Capron, I.; Cathala, B. Surfactant-Free High Internal Phase Emulsions Stabilized by Cellulose Nanocrystals. Biomacromolecules 2013, 14, 291-296. [CrossRef]

40. Bondeson, D.; Mathew, A.; Oksman, K. Optimization of the isolation of nanocrystals from microcrystalline cellulose by acid hydrolysis. Cellulose 2006, 13, 171-180. [CrossRef]

41. Beck-Candanedo, S.; Roman, M.; Gray, D.G. Effect of reaction conditions on the properties and behavior of wood cellulose nanocrystal suspensions. Biomacromolecules 2005, 6, 1048-1054. [CrossRef]

42. Habibi, Y.; Lucia, L.A.; Rojas, O.J. Cellulose Nanocrystals: Chemistry, Self-Assembly, and Applications. Chem. Rev. 2010, 110, 3479-3500. [CrossRef]

43. Li, B.; Xu, W.; Kronlund, D.; Maattanen, A.; Liu, J.; Smatt, J.-H.; Peltonen, J.; Willfor, S.; Mu, X.; Xu, C. Cellulose nanocrystals prepared via formic acid hydrolysis followed by TEMPO-mediated oxidation. Carbohydr. Polym. 2015, 133, 605-612. [CrossRef]

44. Phanthong, P.; Karnjanakom, S.; Reubroycharoen, P.; Hao, X.; Abudula, A.; Guan, G. A facile one-step way for extraction of nanocellulose with high yield by ball milling with ionic liquid. Cellulose 2017, 24, 2083-2093. [CrossRef]

45. Sirvio, J.A.; Visanko, M.; Liimatainen, H. Acidic Deep Eutectic Solvents As Hydrolytic Media for Cellulose Nanocrystal Production. Biomacromolecules 2016, 17, 3025-3032. [CrossRef]

46. Zhang, X.L.; Yang, W.H.; Blasiak, W. Modeling Study of Woody Biomass: Interactions of Cellulose, Hemicellulose, and Lignin. Energy Fuels 2011, 25, 4786-4795. [CrossRef]

47. De Rodriguez, N.L.G.; Thielemans, W.; Dufresne, A. Sisal cellulose whiskers reinforced polyvinyl acetate nanocomposites. Cellulose 2006, 13, 261-270. [CrossRef] 
48. Kuramae, R.; Saito, T.; Isogai, A. TEMPO-oxidized cellulose nanofibrils prepared from various plant holocelluloses. React. Funct. Polym. 2014, 85, 126-133. [CrossRef]

49. Saito, T.; Isogai, A. TEMPO-mediated oxidation of native cellulose. The effect of oxidation conditions on chemical and crystal structures of the water-insoluble fractions. Biomacromolecules 2004, 5, 1983-1989. [CrossRef]

50. Li, W.; Zhao, X.; Huang, Z.; Liu, S. Nanocellulose fibrils isolated from BHKP using ultrasonication and their reinforcing properties in transparent poly (vinyl alcohol) films. J. Polymer Res. 2013, 20. [CrossRef]

51. Chen, W.S.; Yu, H.P.; Liu, Y.X. Preparation of millimeter-long cellulose I nanofibers with diameters of 30-80 nm from bamboo fibers. Carbohydr. Polym. 2011, 86, 453-461. [CrossRef]

52. Segal, L.; Creely, J.J.; Martin, A.E.; Conrad, C.M. An Empirical Method for Estimating the Degree of Crystallinity of Native Cellulose Using the X-Ray Diffractometer. Text. Res. J. 1959, 29, 786-794. [CrossRef]

53. Kasiri, N.; Fathi, M. Production of cellulose nanocrystals from pistachio shells and their application for stabilizing Pickering emulsions. Int. J. Biol. Macromol. 2018, 106, 1023-1031. [CrossRef]

54. Jiang, F.; Hsieh, Y.-L. Chemically and mechanically isolated nanocellulose and their self-assembled structures. Carbohydr. Polym. 2013, 95, 32-40. [CrossRef]

55. Salas, C.; Nypelo, T.; Rodriguez-Abreu, C.; Carrillo, C.; Rojas, O.J. Nanocellulose properties and applications in colloids and interfaces. Curr. Opin. Colloid Interface Sci. 2014, 19, 383-396. [CrossRef]

56. Qing, W.; Wang, Y.; Wang, Y.; Zhao, D.; Liu, X.; Zhu, J. The modified nanocrystalline cellulose for hydrophobic drug delivery. Appl. Surf. Sci. 2016, 366, 404-409. [CrossRef]

57. Chandra, J.C.S.; George, N.; Narayanankutty, S.K. Isolation and characterization of cellulose nanofibrils from arecanut husk fibre. Carbohydr. Polym. 2016, 142, 158-166. [CrossRef]

58. Liu, C.; Li, B.; Du, H.; Lv, D.; Zhang, Y.; Yu, G.; Mu, X.; Peng, H. Properties of nanocellulose isolated from corncob residue using sulfuric acid, formic acid, oxidative and mechanical methods. Carbohydr. Polym. 2016, 151, 716-724. [CrossRef]

59. Sain, M.; Panthapulakkal, S. Bioprocess preparation of wheat straw fibers and their characterization. Ind. Crop. Prod. 2006, 23, 1-8. [CrossRef]

60. Tripathi, A.; Ferrer, A.; Khan, S.A.; Rojas, O.J. Morphological and Thermochemical Changes upon Autohydrolysis and Microemulsion Treatments of Coir and Empty Fruit Bunch Residual Biomass to Isolate Lignin-Rich Micro- and Nanofibrillar Cellulose. ACS Sustain. Chem. Eng. 2017, 5, 2483-2492. [CrossRef]

61. Luzi, F.; Puglia, D.; Sarasini, F.; Tirillo, J.; Maffei, G.; Zuorro, A.; Lavecchia, R.; Kenny, J.M.; Torre, L. Valorization and extraction of cellulose nanocrystals from North African grass: Ampelodesmos mauritanicus (Diss). Carbohydr. Polym. 2019, 209, 328-337. [CrossRef] [PubMed]

62. Camargo, L.A.; Pereira, S.C.; Correa, A.C.; Farinas, C.S.; Marconcini, J.M.; Mattoso, L.H.C. Feasibility of Manufacturing Cellulose Nanocrystals from the Solid Residues of Second-Generation Ethanol Production from Sugarcane Bagasse. Bioenergy Res. 2016, 9, 894-906. [CrossRef]

63. Saito, T.; Nishiyama, Y.; Putaux, J.-L.; Vignon, M.; Isogai, A. Homogeneous suspensions of individualized microfibrils from TEMPO-catalyzed oxidation of native cellulose. Biomacromolecules 2006, 7, 1687-1691. [CrossRef] [PubMed]

64. French, A.D.; Cintron, M.S. Cellulose polymorphy, crystallite size, and the Segal Crystallinity Index. Cellulose 2013, 20, 583-588. [CrossRef]

65. Marett, J.; Aning, A.; Foster, E.J. The isolation of cellulose nanocrystals from pistachio shells via acid hydrolysis. Ind. Crop. Prod. 2017, 109, 869-874. [CrossRef]

66. Kargarzadeh, H.; Ahmad, I.; Abdullah, I.; Dufresne, A.; Zainudin, S.Y.; Sheltami, R.M. Effects of hydrolysis conditions on the morphology, crystallinity, and thermal stability of cellulose nanocrystals extracted from kenaf bast fibers. Cellulose 2012, 19, 855-866. [CrossRef]

67. Ilyas, R.A.; Sapuan, S.M.; Ishak, M.R. Isolation and characterization of nanocrystalline cellulose from sugar palm fibres (Arenga Pinnata). Carbohydr. Polym. 2018, 181, 1038-1051. [CrossRef]

68. Reddy, K.O.; Maheswari, C.U.; Reddy, D.J.P.; Rajulu, A.V. Thermal properties of Napier grass fibers. Mater. Lett. 2009, 63, 2390-2392. [CrossRef]

69. Yang, H.; Yan, R.; Chen, H.; Lee, D.H.; Zheng, C. Characteristics of hemicellulose, cellulose and lignin pyrolysis. Fuel 2007, 86, 1781-1788. [CrossRef] 
70. Fukuzumi, H.; Saito, T.; Wata, T.; Kumamoto, Y.; Isogai, A. Transparent and High Gas Barrier Films of Cellulose Nanofibers Prepared by TEMPO-Mediated Oxidation. Biomacromolecules 2009, 10, 162-165. [CrossRef]

71. Wang, N.; Ding, E.; Cheng, R. Thermal degradation behaviors of spherical cellulose nanocrystals with sulfate groups. Polymer 2007, 48, 3486-3493. [CrossRef]

72. Wang, H.; Li, D.; Yano, H.; Abe, K. Preparation of tough cellulose II nanofibers with high thermal stability from wood. Cellulose 2014, 21, 1505-1515. [CrossRef]

73. Yu, H.; Qin, Z.; Liang, B.; Liu, N.; Zhou, Z.; Chen, L. Facile extraction of thermally stable cellulose nanocrystals with a high yield of $93 \%$ through hydrochloric acid hydrolysis under hydrothermal conditions. J. Mater. Chem. A 2013, 1, 3938-3944. [CrossRef]

74. Cherian, B.M.; Pothan, L.A.; Nguyen-Chung, T.; Mennig, G.; Kottaisamy, M.; Thomas, S. A novel method for the synthesis of cellulose nanofibril whiskers from banana fibers and characterization. J. Agric. Food Chem. 2008, 56, 5617-5627. [CrossRef] [PubMed]

(C) 2019 by the authors. Licensee MDPI, Basel, Switzerland. This article is an open access article distributed under the terms and conditions of the Creative Commons Attribution (CC BY) license (http://creativecommons.org/licenses/by/4.0/). 